Revista Portuguesa de Ciência Política | Portuguese Journal of Political Science ISSN: 1647-4090 | ISSN-e: 2184-2078 | 2018, Número 9, Páginas 141-146 DOI: $10.33167 / 2184-2078 . R P C P 2018.9 /$ pp.141-146

\title{
Contra a Democracia
}

\author{
POR Orlando Coutinho* \\ * Universidade do Minho, Portugal
}

Brennan, J. (2017). Contra a Democracia. Lisboa: Gradiva.

\section{Proémio sobre o interesse do tema}

O Brexit, a eleição de Donald Trump, os impulsos da extrema direita na Europa e a degradação institucional na Venezuela levam muitos académicos e pensadores a pôr a democracia no divã e a tentar perceber o que tem falhado para que - em níveis diferentes e de acordo com os exemplos facultados - os dados vitais do sistema democrático, dito ocidental, sofram algumas transmutações.

Destas "psicoterapias políticas" resultam vários estudos e teorias, com maior ou menor fundamentação, para aferir se o sistema democrático já deu tudo o que tinha a dar e "necessitamos" de outro, ou se - por seu turno - há espaços reformistas que levem a uma condução mais aprofundada do diaporama institucional de molde a que ele responda às necessidades que - o principal desígnio do sistema, o povo, vai apresentando.

Da América surgiu um pensamento há muito em laboratório: a epistocracia. Uma espécie de tecnocracia política conduzida por "conselhos de sábios" que colocaria travões às decorrências habituais das democracias. A síntese, deste pensamento, vem escalpelizada e argumentada neste livro, Contra a Democracia. Tem edição portuguesa, a primeira, datada de junho de 2017, pela Gradiva e merece uma visita. 


\section{O autor}

O autor, Janson Brennan, doutorou-se na Universidade do Arizona em Filosofia, sendo que, dedica as suas investigações, mormente, à filosofia política e à ética aplicada. É professor em várias Universidades e conferencista. Terei oportunidade de defender, nas curtas conclusões que expenderei - já que o objeto desta análise se trata de uma recessão - que o "catalogo" no campo dos utilitaristas.

Mas, como não conhecemos a obra sem o "perfil poético" do autor, uma curta visita à sua página pessoal na internet revela que o resultado deste livro não decorre de um espasmo, antes, de uma reflexão consolidada, argumentada e escrita sobre o tema que discorre ao longo de mais de trezentas páginas. De facto, o filósofo, de mote próprio ou em parceria, tem já um conjunto lato de textos sobre os quais vai apontando defeitos ao sistema democrático e os "desejos" de ver experimentado um outro "instrumento" ao serviço de uma "episteme imaculada" que promova resultados de bem-estar social superiores àqueles que foram atingidos pela democracia.

Com argumentos incisivos e provocatórios - como o título da obra indica Brennan, procura alicerçar um pensamento coerente que justifique, como o próprio apela, a uma adesão, dos vários quadrantes, ao "martelo" que prega melhor do que aquele com que vivemos.

\section{Os nove argumentos do livro}

Convém, pois, dissecar, um pouco mais prolixamente, o que são as ideias essenciais do autor.

Logo no prefácio a objetividade do filósofo é notável. Além de demonstrar o que acima aludi, ou seja, que as suas ideias são o corolário de pensamentos anteriores, nomeadamente em livros que aborda a ética do voto e o voto obrigatório, diz claramente ao que vem: mostrar que a epistocracia (à letra, o poder da episteme, ou do conhecimento metodologicamente pensado) é - normativamente - superior, ao poder do povo, democracia, que está aturdida de eleitores incompetentes. Diz também que a política, sendo má, deveria merecer cada vez menos a atenção das pessoas.

Mas comecemos pela análise dos nove argumentos expendidos, sendo que o primeiro capítulo se afigura como a trave mestra da condução da obra e, como tal, a merecer atenção redobrada.

Como introdução argumentativa, o autor, começa por apresentar Jonh Stuart Mill, utilitarista influenciado por Jeremy Bentham, dizendo que a melhor forma de governo é aquela que produz melhores resultados e que tal evidenciaria um envolvimento progressivo dos cidadãos que se elevariam com essa forma de participação. Claro que a última asserção, mereceu, desde logo, o contraponto do autor através do sustentáculo "schumpteriano" com uma certa diabolização da política, nomeadamente da democracia, fator que não o preocupa já que noutros trabalhos (Brennan $2017,14)$ foi discorrendo sobre o que batizou como "anarquismo cooperativo".

Centra-se, para início, numa "rotulação" dos cidadãos eleitores em três níveis diferenciados, a saber: os hobbits - numa clara referência ao "Senhor dos Anéis" que têm um papel central, apesar de, aprioristicamente, serem um povo secundário, 
representam, do ponto de vista eleitoral, os que são desprovidos de conhecimento e sustentação política. Os hooligans são a "entourage" das tribos político-partidárias. Com alguma formação, usam-na para "cerrar fileiras clubistas", em torno das suas próprias ideias, acossando a contraparte com crispação latente sobre os temas em discussão. Por fim os vulcanos, cujo conhecimento científico é elevado e que conseguem ver o fenómeno político, globalmente considerado, com o distanciamento intelectual sobre as melhores opções em jogo. Nesta nomenclatura, a tabulação é segundo o autor - praticamente binária entre "Hobbits e hooligans" - que é aliás o título do primeiro capítulo - num quase "50/50" que deixa pouca margem para os mais preparados. Este excesso de competição dos grupos iniciais faz diminuir, para Brennan, as loas ao "triunfalismo democrático", colocando todos em perigo. Ora é esse perigo latente que já tem eclodido em crise económicas que afetam a globalidade dos cidadãos que tem de ser travado e substituído por um modelo que garanta confiabilidade institucional. Começa então, Brennan, a defender a epistocracia, uma espécie de "iluminismo" ao jeito da preposição platónica do "Filósofo-Rei". Na certeza que esta postulação "helénica" não veria efeitos práticos no quotidiano, argumenta com formas possíveis de funcionamento: sufrágios ora restritos, ora plurais; sistemas pré-estabelecidos para o exercício do voto com ponderação de decisões em função de conhecimentos políticos testados e verificados ou por fim, uma espécie de "consistórios sapienciais" com poder de veto sobre decisões tomadas democraticamente.

Claro está que estas medidas analisadas sem outros contextos de "contrapesos democráticos”, afiguram-se polémicas e com necessidade de sustentação. Neste particular, Brennan, socorre-se de um outro filósofo com quem habitualmente trabalha, Estlund, que para o efeito alicerça-se em três pilares: a verdade, assumindo que há respostas corretas a situações políticas concretas; o conhecimento, i.e., há cidadãos com mais competências e saber para discutir e decidir sobre determinados temas; e por fim, a autoridade, ou seja, quem sabe mais deve poder decidir sobre os outros. A estes o autor acrescenta um paralelo ao último usando-o "à contrária”, a saber, a anti-autoridade - que significaria que quem não sabe sobre um tema, neste caso político, não deve poder decidir sobre ele, ou seja, votar. Esta última argumentação é que se torna o mote para os capítulos/argumentos seguintes. Como pode - quem não sabe - ter tamanha preponderância em decisões que competem a todos?

Esta dúvida fá-lo colocar a silaba tónica nos eleitores, ou seja, naqueles que escolhem a vida da comunidade. Não tem pejo em nomeá-los como "nacionalistas ignorantes, irracionais, desinformados" que é aliás o mote do seu segundo argumento. E que esta ignorância latente tem uma justificação induzida pelo próprio sistema. Chama-lhe ele a "ignorância racional". Para o investigador, os custos esperados em obter uma informação ponderosa sobre variadíssimas matérias que se possam colocar ao eleitor em posição de decidir em consciência, são superiores aos "ganhos" que este obtém, na medida em que ele, individualmente considerado, vale um voto e outro eleitor - que em igual medida não proceda a este esforço informativo - consegue um peso igual na decisão representativa. Ou seja, há uma tendência ao desinteresse pela busca de informação detalhada e fidedigna. Aliás, o autor escalpeliza - com base em estudos - por grupos sociais, geográficos, étnicos e de género a “incultura 
política", sugerindo de novo a "anáfora": podem estes cidadãos votar como os que estão bem informados?

Segundo o autor, mesmo que o desejo de se inteirar no fenómeno político passasse pelo interesse em ter um papel político mais ativo, o autor desaconselha, já que, como terceiro argumento refere que "a participação política corrompe". Com recurso a estudos para desmontar a democracia participativa e deliberativa, o investigador procura afirmar que, apesar de reconhecer que quem vota está mais informado do que quem se abstém, as diferentes formas de participação política tendem - mais do que educar - a "hooliganizar" os cidadãos. Ou seja, a torná-los mais adeptos de fação e conflituosos do que informados e prontos a agir sem parcialidades para o bem comum ao invés do bem do grupo.

E por isso tende a achar que as considerações que fazem o sustentáculo filosófico sobre as liberdades políticas são exageradas, já que a liberdade de participação política não significa consentimento absoluto à governação que, por sua vez, se faz em função de interesses marginais. A participação, refere, não amplia a autonomia individual, nem impede uns de tentarem dominar os outros e que, portanto, não são o caminho da busca de um sentido de justiça e de vida boa. Ou seja, na diferença entre os eleitores, que escolhem, e os governantes, que executam, o poder dilui-se. Dá-se no coletivo o que se retira no individual o que consequentemente, afirma, deixa de poder-se fazer a crítica à epistocracia enquanto sistema que retira poder individual. Por isso conclui como terceiro argumento que "A política não dá poder a si nem a mim".

$\mathrm{Na}$ passagem seguinte, o autor tenta "desmontar" o que designa de argumentos semióticos em relação à democracia. Vai citando uma série de teóricos políticos (Rawls, 2013) que atribuem ao voto, um significado de autoestima do cidadão que extravasa ao campo simbólico da igualdade. Para Brennan, não se trata de argumentos semioticamente imorais aqueles que defendem o voto limitado ao conhecimento; tal como é preciso ter licença para conduzir ou mais apuradamente para exercer profissões, como medicina, o voto, deveria ser pré-escrutinado a quem revele preparação, já que este seu quinto argumento revela: “a democracia não é um poema” e a decisão sobre as escolhas representativas afetam a todos.

E é por isso que clama, como sexto argumento, pelo "Direito a um governo competente", onde haja condições presuntivas ao direito de governar, i.e., obter condições políticas que dimanem de órgãos competentes (com informação detalhada e com capacidade de analisar e decidir tecnicamente em favor do bem comum) e possam ser vistas como legitimas e passíveis de autoridade, do mesmo modo que os arguidos têm direito a juízos competentes. Pensa que a epistocracia estará em melhores condições de assegurar estes pressupostos do que a democracia.

No sétimo argumento, onde o autor questiona “A Democracia é competente?", procura assinalar que os pensadores democráticos - que defendem que este sistema mesmo que tenha uma maioria de votantes incompetentes, acaba por produzir decisões competentes - não têm razão para pensar que a democracia é competente e o melhor dos sistemas. Procura diluir os três teoremas matemáticos — "Milagre da 
agregação", "Júri de Condorcet" e "Hong Page" que correspondem às conclusões ora afirmadas (Brennan, 2017, pp. 242-243).

E por tudo isto defende um governo epistocrático, apontando com detalhe - e aqui abstenho-me de considerandos pormenorizados sobre a forma como o autor o faz para não retirar o interesse a quem queira de facto ler e interpretar, mote próprio e na totalidade, o livro - as diferentes formas de um, como oitavo argumento, "Governo de Sábios”, a saber: sufrágios restritos ou votações plurais, credenciação aleatória, sufrágio universal com veto epistocrático e um governo por oráculo simulado.

Em súmula, o autor apresenta uma espécie de epílogo desafiante. Tendo em conta que explica as fragilidades dos votantes e de todo o sistema democrático, apontando as vantagens de um sistema de tipo "iluminista", os que continuam a fazer opções erradas tornam-se, como nono argumento, seus "Inimigos cívicos" - já que, as suas reiteradas más opções, o prejudicam individual e coletivamente, quando, na (sua) verdade, existem alternativas melhores como a epistocracia."

\section{Conclusão}

Como nota conclusiva pode dizer-se que o tema tratado neste livro e o arrojo com que o autor o fez, deve merecer a atenção dos democratas mais convictos. Em primeira instância, há sinais claros, em várias esferas da vida ocidental, que este modelo de organização política tem adversários fortes e multiformes capazes de argumentar com recurso a pensamento académico fundamentado sobre alternativas ao regime vigente. Depois, porque a radicalização dos modelos totalitários conhecidos, pode fazer com que se olhe com simpatia para outros, "mais suaves", mas que, como o próprio título da obra o deixa subentender, são antidemocráticos.

Contudo, este tipo de ensaios, como o próprio filósofo o reconhece, carece da via experimental que acaba por traduzir muitas das premissas em meras especulações sem verificabilidade empírica conhecida. O que suscita questões.

Por exemplo, o autor não explicou se queria a implementação de uma epistocracia por via democrática. Seria um paradoxo - face ao argumentado pelo próprio - mas com legitimidade; não concluiu se seria por via de Golpe de Estado de cariz militar; se seria por revolução armada ou pacífica... Talvez seja um ponto a esclarecer em próximas edições.

Outra das críticas que se pode associar à presente obra é que ela incide muito sobre a realidade norte americana. Os estudos empíricos citados, a análise social evidenciada, a panorâmica eleitoral retratada, a realidade sistémico-política descrita, resulta, sobretudo, desta visão concentrada do que é a sociedade dos Estados Unidos, podendo o leitor especular sobre as diferenças face à(s) Europa(s).

Por fim e não menos importante, a questão de saber o que é bem comum e um sistema justo é uma variante que separa as ideologias entre si; saber se, como exemplo, a política da Troika foi boa para Portugal, dividirá sempre as diferentes partes em contenda, por conseguinte sem se saber o que é o tal "bem comum", o certo e o errado e portanto o que seria, naquela experiência que Portugal viveu, de tipo epistocrático já que muitas medidas eram sujeitas a "visto prévio", uma discussão infinita que certamente colidiria com as variáveis essenciais da democracia. 
Como já o havia dito, ab initio, considero Janson Brennan um utilitarista. Ao metaforizar a democracia com um martelo está, tão só, a colocá-la no campo do instrumento; instrumento esse, ao jeito de Richard Brandt, que mais não serve para dar uma satisfação maior ao global dos cidadãos (Rosas, 2008, pp. 19-20) bem ao contrário das tradições democráticas principais que remetem a democracia como um fim em si mesmo (citar) dando ao Homem a dignidade interpares que o coloca em ponto de partida igual na sua caminhada social.

É uma obra a merecer atenção e certamente aos debates académicos que se lhe seguirão.

\section{Referências}

Brennan, J. (2017). Contra a Democracia. Lisboa: Gradiva.

Rawls, J. (2013). Uma teoria da Justiça (3.a ed.). (C. P. Correia, Trans.). Lisboa: Editorial Presença.

Rosas, J. C. (2008). Manual de Filosofia Política. Coimbra: Almedina. 